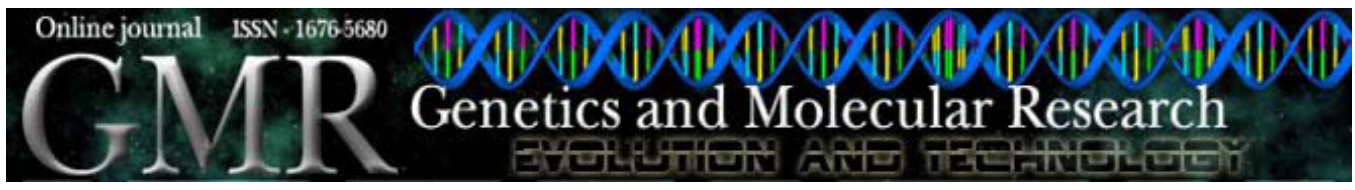

\title{
Cloning and quantitative expression analysis of drought-induced genes in soybean
}

\author{
R. Stolf-Moreira ${ }^{1}$, M.E. Medri ${ }^{2}$, N. Neumaier ${ }^{3}$, N.G. Lemos ${ }^{1}$, R.L. Brogin ${ }^{3}$, \\ F.C. Marcelino ${ }^{3}$, M.C.N. de Oliveira ${ }^{3}$, J.R.B. Farias ${ }^{3}$, R.V. Abdelnoor ${ }^{3}$ and \\ A.L. Nepomuceno ${ }^{3}$ \\ ${ }^{1}$ Departamento de Biologia Geral, Programa de Genética e Biologia Molecular, \\ Universidade Estadual de Londrina, Londrina, PR, Brasil \\ ${ }^{2}$ Departamento de Biologia Animal e Vegetal, \\ Universidade Estadual de Londrina, Londrina, PR, Brasil \\ ${ }^{3}$ Embrapa Soja, Londrina, PR, Brasil \\ Corresponding author: F.C. Marcelino \\ E-mail: francm@cnpso.embrapa.br
}

Genet. Mol. Res. 9 (2): 858-867 (2010)

Received November 15, 2009

Accepted February 12, 2010

Published May 11, 2010

DOI 10.4238/vol9-2gmr701

\begin{abstract}
We determined the expression levels of DREB transcription factor (Gmdreb1) and of the genes Gmgols, Gmpip1b, Gmereb, and Gmdefensin in drought-tolerant (MG/BR46-Conquista) and droughtsensitive (BR16) genotypes of soybean, during drought. The trial was carried out in a controlled-environment chamber, set up to provide drought conditions. Sequences of Arabidopsis thaliana DREB-family proteins were used to build a phylogenetic tree through the alignment of the conserved regions near the AP2 domain. We found that Gmdreb1 is similar to Atrap2.1, which is located near the AtDREB1 and AtDREB2 families. The amplified fragment was cloned and sequenced; alignment with the sequence available at Genbank showed total similarity. Expression analysis showed that under drought: a) Gmdrebl expression increased in leaves and roots of both genotypes and expression level changes occurred that were correlated with the length of the water-deficit period; b) there
\end{abstract}


were increased expression levels of Gmdefensin in roots of MG/BR46; c) expression of Gmgols increased in leaves and roots of the two genotypes; d) Gmpip1b expression generally increased, except in roots of BR16, and e) the same was found for Gmereb, except in roots of MG/BR46.

Key words: Drought; Glycine max; Gene expression; Quantitative PCR; Dreb gene; Water deficit

\section{INTRODUCTION}

Abiotic stresses, such as drought, can limit the geographical distribution of plants and limit the growth and yield of economically important species. Substantial efforts have been devoted to determine the nature of the injury caused by these stresses and the plant-protection mechanisms involved in tolerance responses (Bray, 2004). Some genes are up-regulated and others are down-regulated in plants under drought stress. This regulation occurs at distinct levels, from the moment of stress detection to the production of biologically active proteins (Shinozaki and Yamaguchi-Shinozaki, 2007). The scientific community has attempted to determine how plants detect water deficit and process information to alter gene expression.

An important step forward was the identification of a cis-acting dehydration responsive element (DRE), the function of which is important for the expression of genes responding to dehydration in Arabidopsis thaliana (Yamaguchi-Shinozaki and Shinozaki, 1994). This element has a C-repeat sequence of $5 \mathrm{bp}$ (CCGAC) that is present in one or multiple copies in the promoter region of many plant genes related to dehydration response (Baker et al., 1994).

The transcription factor DREB1 (dehydration-responsive element-binding protein) specifically interacts with the element DRE and induces the expression of genes involved in the stress response of $A$. thaliana. Twelve stress-induced genes were identified as DREB1 target genes by Seki et al. (2001), and Fowler and Tomashow (2002) described 41 genes as DREB target genes. The function of some of these gene products seems to be related to structure and basic cell function maintenance during water deficit, low temperatures and high salinity (Shinozaki and Yamaguchi-Shinozaki, 1996; Kasuga et al., 2004).

Differential expression of genes involved in defense mechanisms against cell dehydration plays a key role in water-deficit tolerance. The understanding of how the expression of individual genes contributes to the final response in cellular, physiological and agronomical terms has enabled the design of strategies for developing plants that are more tolerant to water deficit. The defense mechanisms involved in this process seem to be similar across the plant kingdom. Therefore, research using model plants, such as $A$. thaliana and tobacco (Nicotiana tabacum), can help to identify genes with key functions in defense mechanisms in other plant species. Techniques such as real-time quantitative polymerase chain reaction (RT-qPCR), allow precise quantification of the mRNA levels of genes of interest when their expressions are compared under various conditions or treatments (Volkov et al., 2003).

Hence, the objectives of this study were to investigate the expression levels of a soybean DREB transcription factor (Gmdreb1), to clone it for further studies and to evaluate the expression of genes that are DREB regulated in A. thaliana, such as Gmgols, Gmpip1b, Gmereb, and Gmdefensin, in two soybean genotypes, MG/BR46 (Conquista) (referred to as MG/BR46), and BR16, during periods of water deficit, to elucidate their expression profiles. 


\section{MATERIAL AND METHODS}

\section{Sequencing}

A sequence showing a high degree of similarity with $A t$ DREB transcription factor was detected in soybean at Genbank, namely accession No. AF514908.1. A phylogenetic analysis was performed in the protein sequences of $A$. thaliana containing the conserved AP2 domain, using the molecular evolutionary genetic analysis (MEGA) version 3.1 software (Kumar et al., 2004). To obtain the coding region for Gmdreb1, primers were designed from start and stop codons of the sequence, corresponding to forward: 5' TTT AAT CCG TTA TAT GCC ACC 3', and reverse: 5' TAT CAA TCT TGA AGC TCT TCG 3', producing a fragment of $604 \mathrm{bp}$.

PCR were performed using a Perkin Elmer 9600 thermocycler (Perkin Elmer, Massachusetts, CA, USA), and samples were purified with a Wizard SV Gel Kit (Promega, Carlsbad, CA, USA), according to manufacturer instructions. Cloning was done using the pGEM-T Easy Vector kit (Promega), and transformation was carried out according to Miller and Nickoloff (1995), using a micro pulser electroporator (Bio-Rad, Foster City, CA, USA). Sequencing of insert-containing plasmids was performed by PCR-cycle sequencing, using the ABI Prism Big Dye Terminator Cycle sequencing kit (Applied Biosystems, Foster City, CA, USA), and the fragments were separated using an ABI Prism 3100 (Applied Biosystems). The chromatograms were passed through a base-calling process using phred (Ewing et al., 1998), which assigned quality values above 20 to the bases.

\section{Gene-expression analysis}

Gene-expression analysis was performed using RT-qPCR on tissue samples of leaves and roots of soybean plants of drought tolerant and sensitive genotypes, MG/BR46 and BR16, respectively. Nine days after 10 seeds of each genotype were placed in germitest paper rolls, plantlets were moved to a controlled environment chamber and exposed to the air on paper tissue under the chamber conditions $\left(28 \pm 2{ }^{\circ} \mathrm{C}, 60 \% \mathrm{RH} \pm 2^{\circ} \mathrm{C}\right)$ and water stress treatment for $0,1,3$, and $5 \mathrm{~h}$.

At the end of each period, roots were collected, placed in liquid nitrogen, and stored at $-80^{\circ} \mathrm{C}$. Total RNA was extracted using Trizol reagent (Invitrogen, Carlsbad, CA, USA) according to manufacturer instructions and subsequently treated with DNAse (Invitrogen). For reverse transcription and synthesis of the complementary DNA (cDNA), Moloney murine leukemia virus (Invitrogen) reverse transcriptase was used, as described by Schenk et al. (2003).

The Primer Express program version 3.0 (Applied Biosystems) was used to design the primers for RT-qPCR. The primer sequences were determined on the 3' regions of the genes with putative amplicons of 75 to $150 \mathrm{bp}$ (Table 1). The genes used in the expression analysis were chosen based on a literature review, where it was found that, in many species, their differential expression is related to drought tolerance. After the identification of candidate genes, a search for similar sequences in soybean was made, such as: Gmdrebla (dehydration-responsive element-binding protein, Genbank accession No. AF514908.1)-signal-transduction cascade in responses to abiotic stress, Gmdefensin (drought-induced proteinase inhibitor, Genbank accession No. U12150), Gmpiplb (putative channel protein, aquaporin, Genbank accession No. U27347), Gmgols (galactinol synthase, Genbank accession No. AY126715) - a key 
enzyme in raffinose synthesis. The gene for $18 \mathrm{~S}$ rRNA was chosen as the endogenous control (Genbank accession No. X02623.1) for normalization, because its level of expression was shown to be constant in the presence of abiotic stresses (Stolf, 2007).

\begin{tabular}{lll} 
Table 1. Primer sequences of genes utilized in real-time quantitative polymerase chain reation. \\
\hline \multirow{2}{*}{ Genes } & \multicolumn{1}{c}{ Primer sequences } \\
\cline { 2 - 3 } & \multicolumn{1}{c}{ Foward (5'-3') } & Reverse (5'-3') \\
\hline Gmr18SrRNA & AAACGGCTACCACATCCAAG & CCTTCAATGGATCCATCGTTA \\
Gmareb1 & CGACCAGGAGGGCAGTGAT & GCTTTTCGGCGAATGGAAT \\
Gmdefensin & TCATGGGTTCAAAAAGGAGA & GCTTGCAATAAAAGCACAAGC \\
Gmgols & TTTGAGTGACACCAACTGTGG & AACAATGTTTGGTGCAGAAGC \\
\hline
\end{tabular}

The RT-qPCR analysis was performed with a thermocycler, 7300 Real Time System (Applied Biosystems), and the Platinum ${ }^{\circledR} \mathrm{SYBR}^{\circledR}$ Green qPCR SuperMix UDG (Invitrogen). The reaction conditions were $50^{\circ} \mathrm{C}$ for $2 \mathrm{~min}, 95^{\circ} \mathrm{C}$ for $10 \mathrm{~min}, 45$ cycles at $95^{\circ} \mathrm{C}$ for $2 \mathrm{~min}$, $62^{\circ} \mathrm{C}$ for $30 \mathrm{~s}$ and $72^{\circ} \mathrm{C}$ for $30 \mathrm{~s}$; the data were collected in the last phase (extension phase). The $\mathrm{E}=\left[10^{-1 / 1 / \mathrm{lop} e}\right]-1$ formula was used to calculate the reaction efficiency both of the target genes and the endogenous control. The results were captured by the Sequence Detection program (Perkin Elmer) and analyzed by the Relative Expression Software Toll (REST) version 2.0.7 (Pfaffl et al., 2002).

\section{RESULTS AND DISCUSSION}

A fragment of $604 \mathrm{bp}$ was amplified using primers designed for cloning the coding region of the Gmdreb1. After cloning, the fragment was sequenced and its similarity with the coding sequence of the gene Gmdreb1 was verified. The Blastn aligning of the Gmdreb1 nucleotide sequence showed $100 \%$ similarity to the dreb sequence available at Genbank through the accession No. AF514908.1. The conserved regions near the AP2 domain, presented in the phylogenetic tree, were aligned using the ClustalW program (www.ebi.ac.uk/clustalw). The AP2 domain of these transcription factors links to the DRE region located at the promoter region of stress-induced genes. It was found that Gmdreb1 is similar to the Atrap2.1 gene, which is located in the Atdreb1 and Atdreb2.1 families (Figure 1).

The phylogenetic analysis, performed with all peptide sequences containing the conserved AP2 domain of $A$. thaliana available at Genbank, allowed the detection of three distinct groups, DREB1, DREB2 and RAP2.1, the last of which contains Gmdreb1, the object of this study. Studies by Kasuga et al. (1999) showed similarity in the amino acid sequences of proteins $A t \mathrm{DREB} 1 \mathrm{~A}$ and $A t \mathrm{DREB} 2 \mathrm{~A}$. Such similarity is in the 58-amino acid conserved region of the DNA linkage domain, present in a large array of plant gene families, including the proteins EREBPs in tobacco and APETALA (AP2) in A. thaliana, which are involved in the expression of ethylene response and in floral morphogenesis, respectively.

AtDREB1A has a 216-amino acid open reading frame encoding a $24.2-\mathrm{kD}$ protein, whereas $A t$ DREB2A has a 335 -amino acid open reading frame encoding a $37.7 \mathrm{kD}$ protein (Kasuga et al., 1999). Each DREB protein has a basic region at the $\mathrm{N}$-terminal end that can function as a nuclear localizing signal and an acid region at the $\mathrm{C}$-terminal end that can func- 
tion as an activating domain for transcription. These data suggest that each dreb gene encodes a DNA-binding protein that can function as a transcription activator in plants. Also, two homologues of $A t \mathrm{DREB} 1 \mathrm{~A}$ ( $A t \mathrm{DREB} 1 \mathrm{~B}$ and $A t \mathrm{DREB} 1 \mathrm{C})$ were detected in tandem on chromosome 4 of $A$. thaliana (Gilmour et al., 1998), induced by low temperature, and one homologue of $A t$ DREB2A (AtDREB2B), induced by dehydration. Such findings suggest the existence of two independent families of DREB proteins (DREB1 and DREB2) acting as transcription factors in two separate signal-transduction pathways, in response to low temperatures and dehydration.

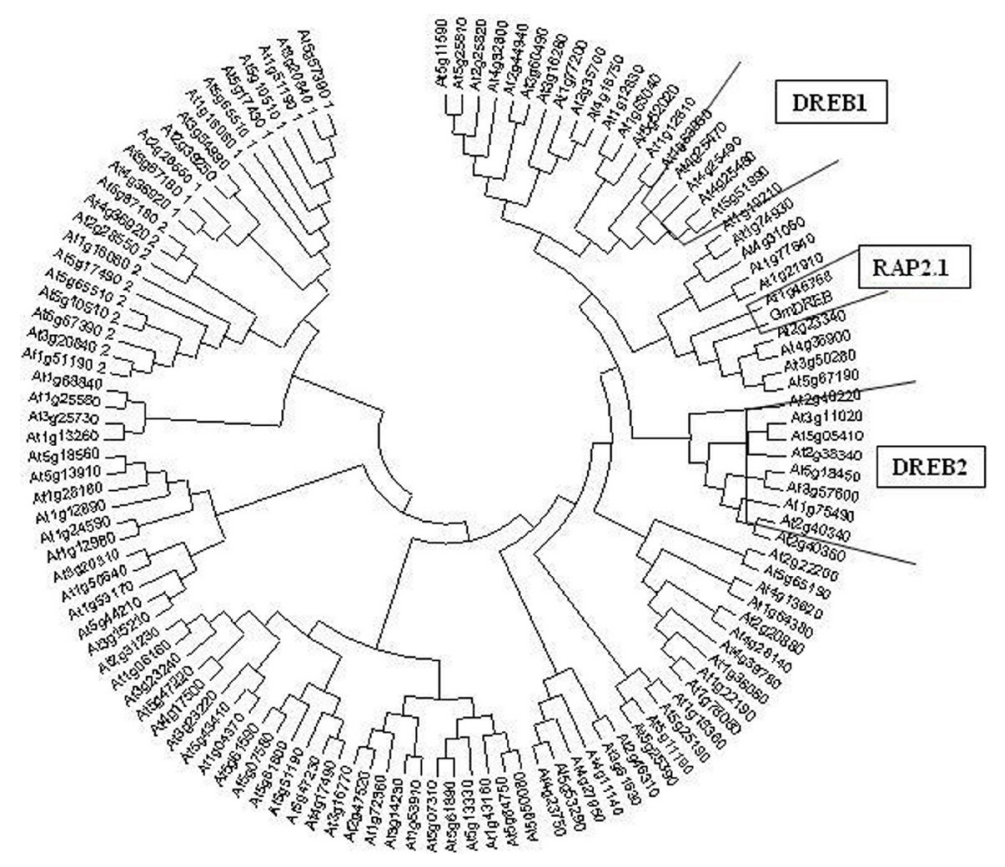

Figure 1. Phylogenetic tree of the DREB family in Arabdopsis thaliana containing the AP2 conserved domain.

Mechanisms of adaptation to cold and drought are highly complex, but some of the metabolic pathways are regulated by abscisic acid, which acts as a second messenger, whereas other paths are abscisic acid-independent (Zhang et al., 2004). The expression of these genes (dreb) can be altered within minutes of application of cold (Gilmour et al., 1998) or drought (Haake et al., 2002) stress. Two proteins containing AP2, RAP2.6 and RAP2.1 domains were also induced by cold (Fowler and Thomashow, 2002). The RAP2.1 promoter, which contains two copies of the CCGAC sequence of the element CRT/DRE, was highly expressed in transgenic $A$. thaliana plants constitutively expressing DREB, suggesting that it can be a target for DREB activators (Fowler and Thomashow, 2002). The RAP2.1 sequence in A. thaliana found at Genbank (accession No. At1g46768) was obtained from plants exposed to cold.

Understanding the molecular-response mechanisms in plants under harsh conditions such as drought is still limited, although the number of genes known to moderate these responses has increased (Kizis et al., 2001). Some of these genes are stress induced and encode 
products that confer tolerance to adverse conditions, whereas others encode upstream regulators acting inside the signaling pathway, controlling the stress response.

Increases in the expression of Gmdreb1 in leaves of MG/BR46, under 1- and 3-h treatments were, respectively, two and three times greater than in the control. In leaves of cultivar BR16 under 1-, 3- and 5-h treatments, the increases in expression were two, two and five times greater than in the control, respectively. The expression in MG/BR46 roots submitted to 1-h treatment increased nine times and, under 3- and 5-h treatments, the increases were 6- and 19fold, respectively (Table 2). In roots of BR16 under 1- and 5-h treatments, the expression levels of the gene Gmdreb1 were eight and three times greater than the control, respectively (Table 3).

\begin{tabular}{|c|c|c|c|c|c|c|}
\hline Gene & & Expression & $95 \% \mathrm{CI}$ & $\mathrm{P}(\mathrm{H} 1)$ & Result & Primer efficiency \\
\hline \multicolumn{7}{|c|}{$\begin{array}{l}\text { Leaf MG/BR46 } \\
\text { (Conquista) genotype }\end{array}$} \\
\hline \multirow[t]{3}{*}{ Gmdrebla } & $1 \mathrm{~h}$ & 2.58 & {$[2.08 ; 3.38]$} & 0.01 & $\mathrm{Up}$ & 1.00 \\
\hline & $3 \mathrm{~h}$ & 3.08 & {$[2.56 ; 3.93]$} & 0.01 & Up & \\
\hline & $5 \mathrm{~h}$ & 0.06 & {$[0.05 ; 0.08]$} & 0.07 & & \\
\hline \multirow[t]{3}{*}{ Gmpiplb } & $1 \mathrm{~h}$ & 10.60 & {$[5.57 ; 20.38]$} & 0.03 & Up & 0.89 \\
\hline & $3 \mathrm{~h}$ & 180.81 & {$[107.55 ; 314.87]$} & 0.00 & $\mathrm{Up}$ & \\
\hline & $5 \mathrm{~h}$ & 0.02 & {$[0.01 ; 0.04]$} & 0.00 & Down & \\
\hline \multirow[t]{3}{*}{ Gmdefensin } & $1 \mathrm{~h}$ & 1.55 & {$[1.00 ; 2.67]$} & 0.10 & & 1.00 \\
\hline & $3 \mathrm{~h}$ & 80.89 & {$[55.57 ; 144.32]$} & 0.00 & $\mathrm{Up}$ & \\
\hline & $5 \mathrm{~h}$ & 0.00 & {$[0.00 ; 0.00]$} & 0.00 & Down & \\
\hline \multirow[t]{3}{*}{ Gmgols } & $1 \mathrm{~h}$ & 157.29 & [31.82; 955.99] & 0.03 & Up & 0.83 \\
\hline & $3 \mathrm{~h}$ & 54.74 & {$[0.77 ; 1270.01]$} & 0.14 & & \\
\hline & $5 \mathrm{~h}$ & 0.55 & {$[0.35 ; 0.77]$} & 0.00 & Down & \\
\hline \multicolumn{7}{|c|}{$\begin{array}{l}\text { Root MG/BR46 } \\
\text { (Conquista) genotype }\end{array}$} \\
\hline \multirow[t]{3}{*}{ Gmdrebla } & $1 \mathrm{~h}$ & 9.41 & {$[6.53 ; 16.11]$} & 0.03 & Up & 1.00 \\
\hline & $3 \mathrm{~h}$ & 6.04 & {$[2.49 ; 13.11]$} & 0.03 & Up & \\
\hline & $5 \mathrm{~h}$ & 19.31 & {$[13.81 ; 31.95]$} & 0.03 & Up & \\
\hline \multirow[t]{3}{*}{ Gmpiplb } & $1 \mathrm{~h}$ & 15.72 & {$[9.24 ; 26.89]$} & 0.03 & Up & 0.89 \\
\hline & $3 \mathrm{~h}$ & 5.42 & {$[0.87 ; 15.59]$} & 0.15 & & \\
\hline & $5 \mathrm{~h}$ & 3.04 & {$[1.76 ; 5.03]$} & 0.03 & Up & \\
\hline \multirow[t]{3}{*}{ Gmdefensin } & $1 \mathrm{~h}$ & 473.83 & {$[244.30 ; 797.97]$} & 0.01 & Up & 1.00 \\
\hline & $3 \mathrm{~h}$ & 317.84 & {$[83.21 ; 700.49]$} & 0.02 & $\mathrm{Up}$ & \\
\hline & $5 \mathrm{~h}$ & 55.95 & {$[40.28 ; 74.45]$} & 0.00 & Up & \\
\hline \multirow[t]{3}{*}{ Gmgols } & $1 \mathrm{~h}$ & 2.73 & {$[0.79 ; 23.61]$} & 0.30 & & 0.83 \\
\hline & $3 \mathrm{~h}$ & 1.65 & {$[0.24 ; 22.86]$} & 0.71 & & \\
\hline & $5 \mathrm{~h}$ & 1.09 & {$[0.19 ; 11.54]$} & 0.90 & & \\
\hline
\end{tabular}

$95 \% \mathrm{CI}=$ confidence interval at $95 \% ; \mathrm{P}(\mathrm{H} 1)=$ probability of the $\mathrm{H} 1$ differential expression hypothesis. The Gm18SrRNA was used as a reference.

The increase in Gmdreb1 expression in plant roots of both genotypes under 1-h treatment implies a more rapid expression response, in comparison to the other periods of exposure. Under 3-h treatment, plant roots of MG/BR46 and BR16 (Tables 2 and 3) showed reductions in the expression levels of the Gmdreb1, reaching values lower than those of the control. For the longest treatment period $(5 \mathrm{~h}), \mathrm{MG} / \mathrm{BR} 46$ plants maintained expression at the same level as in the 3-h treatment. In the leaves of BR16, there were slower and steadier increases in the expression level during the treatment periods, and MG/BR46 plants barely showed any increases. One possible explanation for BR16 leaves and roots differing in expression of Gmdrebl is that the leaves have a defense mechanism to avoid water loss whereas the roots 
are more sensitive since they are usually in the soil and not exposed to open air. Since the treatments were applied in an environment-controlled chamber, the exposed roots dried more quickly and probably senesced more rapidly than did the leaves.

\begin{tabular}{|c|c|c|c|c|c|c|}
\hline Gene & & Expression & $95 \% \mathrm{CI}$ & $\mathrm{P}(\mathrm{H} 1)$ & Result & Primer efficiency \\
\hline \multicolumn{7}{|c|}{ Leaf BR16 genotype } \\
\hline \multirow[t]{3}{*}{ Gmdrebla } & $1 \mathrm{~h}$ & 2.03 & {$[1.52 ; 3.18]$} & 0.03 & Up & 1.00 \\
\hline & $3 \mathrm{~h}$ & 2.48 & {$[2.17 ; 2.96]$} & 0.00 & Up & \\
\hline & $5 \mathrm{~h}$ & 5.58 & {$[4.87 ; 6.79]$} & 0.00 & $\mathrm{Up}$ & \\
\hline \multirow[t]{3}{*}{ Gmpiplb } & $1 \mathrm{~h}$ & 5.97 & {$[3.30 ; 13.33]$} & 0.00 & Up & 0.89 \\
\hline & $3 \mathrm{~h}$ & 28.53 & {$[14.03 ; 52.88]$} & 0.00 & Up & \\
\hline & $5 \mathrm{~h}$ & 20.02 & {$[9.15 ; 52.63]$} & 0.06 & & \\
\hline \multirow{3}{*}{ Gmdefensin } & $1 \mathrm{~h}$ & 9.41 & {$[4.15 ; 29.47]$} & 0.02 & Up & 1.00 \\
\hline & $3 \mathrm{~h}$ & 2.90 & {$[1.76 ; 6.66]$} & 0.00 & Up & \\
\hline & $5 \mathrm{~h}$ & 4.57 & {$[1.30 ; 44.32]$} & 0.00 & Up & \\
\hline \multirow{3}{*}{ Gmgols } & $1 \mathrm{~h}$ & 9.58 & {$[1.56 ; 68.43]$} & 0.00 & Up & 0.83 \\
\hline & $3 \mathrm{~h}$ & 62.77 & {$[15.63 ; 210.24]$} & 0.06 & & \\
\hline & $5 \mathrm{~h}$ & 102.41 & {$[26.79 ; 328.80]$} & 0.00 & Up & \\
\hline \multicolumn{7}{|c|}{ Root BR16 genotype } \\
\hline \multirow{3}{*}{ Gmdrebla } & $1 \mathrm{~h}$ & 8.86 & {$[7.57 ; 10.32]$} & 0.00 & Up & 1.00 \\
\hline & $3 \mathrm{~h}$ & 0.37 & {$[0.24 ; 0.66]$} & 0.00 & Down & \\
\hline & $5 \mathrm{~h}$ & 2.67 & {$[1.91 ; 4.05]$} & 0.00 & Up & \\
\hline \multirow[t]{3}{*}{ Gmpiplb } & $1 \mathrm{~h}$ & 0.98 & {$[0.49 ; 1.65]$} & 0.95 & & 0.89 \\
\hline & $3 \mathrm{~h}$ & 0.00 & {$[0.00 ; 0.00]$} & 0.00 & Down & \\
\hline & $5 \mathrm{~h}$ & 1.04 & {$[0.56 ; 2.15]$} & 0.88 & & \\
\hline \multirow{3}{*}{ Gmdefensin } & $1 \mathrm{~h}$ & 0.56 & {$[0.00 ; 3020.14]$} & 0.75 & & 1.00 \\
\hline & $3 \mathrm{~h}$ & 0.00 & {$[0.00 ; 0.05]$} & 0.10 & & \\
\hline & $5 \mathrm{~h}$ & 0.15 & {$[0.00 ; 13.90]$} & 0.59 & & \\
\hline \multirow[t]{3}{*}{ Gmgols } & $1 \mathrm{~h}$ & 12.68 & {$[1.68 ; 56.94]$} & 0.00 & Up & 0.83 \\
\hline & $3 \mathrm{~h}$ & 0.02 & {$[0.01 ; 0.03]$} & 0.03 & Down & \\
\hline & $5 \mathrm{~h}$ & 9.26 & {$[0.47 ; 59.76]$} & 0.39 & & \\
\hline
\end{tabular}

$95 \% \mathrm{CI}=$ confidence interval at $95 \% ; \mathrm{P}(\mathrm{H} 1)=$ probability of the $\mathrm{H} 1$ differential expression hypothesis. The Gm18SrRNA was used as a reference.

Differential expression of Gmpiplb was observed in both genotypes in the various tissues and treatments. In the leaves of MG/BR46 under 1- and 3-h treatments, its expression increased 10 and 180 times, respectively. However, under 5-h treatment, expression was down-regulated in leaves (Table 2), whereas in roots, although not statistically significant, expression increased five times under the 3-h treatment. In BR16, the expression levels of Gmpip 1 b in leaves submitted to 1- and 3-h treatments were five and twenty-eight times higher than in the controls, respectively (Table 3). In roots, the only difference detected was in MG/ BR46; under 1- and 5-h treatments, the expression of Gmpip $1 b$ was fifteen times and three times higher than in the control, respectively. In the first two periods of treatment ( 1 and $3 \mathrm{~h})$ there was a differential and gradual expression of Gmpip $1 b$ in leaves of both MG/BR46 and BR16 (Tables 2 and 3). However, under 5-h treatment the expression level in MG/BR46 decreased to values smaller than those of the 0 -h control. BR16 plants, although showing lower expression level values of this gene in the 5-h treatment (in relation to the 3-h treatment), maintained the differential expression level in relation to the control. In roots, BR16 did not 
show differential expression of the Gmpip1b gene; however, roots of MG/BR46 also showed increased expression under 1- and 3-h treatments. The same pattern was seen in MG/BR46 leaves. It is suggested that $5 \mathrm{~h}$ under water stress was a critical period for MG/BR46 roots, since they were exposed to open air and may have entered senescence shortly after $3 \mathrm{~h}$.

According to Johansson et al. (2000), the expression of genes encoding aquaporins is regulated in a cell-specific manner, via hormones and by environmental signals such as nematode infection or drought. Over 30 genes encode homologous aquaporins in A. thaliana, and the PIP family is located mainly in the plasma membrane. Studies have shown that aquaporins are multifunctional transporters of solutes and water (Maurel and Chrispeels, 2001). The transport of gases, such as $\mathrm{CO}_{2}$ and $\mathrm{NH}_{3}$, through aquaporins supports the suggestion that these proteins may be important in leaves and in root-nodule systems (Tyerman et al., 1999).

Transgenic A. thaliana (Kaldenhoff et al., 1998) and Nicotiana tabacum (Siefritz et al., 2001) plants with down-regulation of gene pip1, showed reduced osmotic water permeability in the protoplasts of leaves and roots, respectively, compared to control plants (Martre et al., 2002). Besides, plants with $A$. thaliana pip $1 b$ antisense displayed dry root mass five times larger than did control plants (Kaldenhoff et al., 1998). In another study, the A. thaliana pip2 gene was over-expressed in tobacco, reducing water exchange through the plasma membrane in transformed plants compared to controls (Shukla and Chrispeels, 1998).

In leaves of MG/BR46 submitted to $3 \mathrm{~h}$ of water deficit, expression of the Gmdefensin gene increased eighty times, whereas, in the same tissue of BR16, increases in expression were nine, two and three times when submitted to 1-, 3- and 5-h treatments, respectively. In the roots of genotype MG/BR46, in the 1-h treatment, Gmdefensin expression increased 470 times, and then declined in 3- and 5-h treatments to 317 and 57 times greater than in the control, respectively. No differences in Gmdefensin gene expression were detected in the roots of BR16 submitted to these treatments, compared to the control.

In response to water stress, MG/BR46 showed increases in expression levels of Gmdefensin that were considerably higher in roots than in leaves. However, the expression in the roots decreased slowly to the last treatment period (5 h). In BR16, Gmdefensin expression increased only in leaves with the 1-h treatment.

Defensins are a family of small, cysteine-rich proteins that have antimicrobial activity, protecting cell structures from attack by microorganisms. A recent study pointed out that defensins are also involved in abiotic-stress responses (Maitra and Cushman, 1998). This same study detected a 10-fold increase in the expression of a defensin-encoding gene in a drought-tolerant soybean genotype, compared to a sensitive counterpart, when under water deficit. Yamada et al. (1997) also detected increased expression of defensins in tobacco-relative Nicotiana excelsior under salt stress, showing that the gene is involved in the response to cell dehydration.

In relation to the control, leaves of MG/BR46 under the 1-h treatment showed increased expression of Gmgols of 157 times. For leaves of BR16 under 1- and 5-h treatments, the expression levels were nine and 102 times higher, respectively. In BR16 roots under 1-h treatment, the increase was 12 -fold, and after $5 \mathrm{~h}$ it increased 9-fold.

Gmgols, which encodes galactinol synthase, showed increased expression in leaves of the MG/BR46 genotype in the early hours of stress, whereas no differences in expression were seen in the roots. In contrast, in roots and leaves of the sensitive genotype, BR16, distinct expression of the gene was observed in all stress periods. Galactinol synthase plays a key role in biosynthesis of raffinose oligosaccharides and soluble carbohydrates, which are 
components of sugars transported through the phloem in higher plants (Haritatos et al., 2000). The accumulation of this carbohydrate in plants is associated with tolerance to environmental stresses such as cold, heat, and dehydration (Downie et al., 2003). A number of studies have shown increased expression of gols in response to abiotic stresses, as in the vegetative tissues of cold-exposed common bean (Phaseolus vulgaris) and in rice (Oryza sativa) submitted to cold and osmotic stresses (Liu et al., 1998).

It is noteworthy that leaves of MG/BR46 showed lower expression of all these genes with the 5-h treatment. It is suggested that $5 \mathrm{~h}$ was a critical period for MG/BR46, because the plants were already senescent, or their metabolism could be increased for physiologic processes. In roots, only Gmdrebla showed the highest expression in the last period (5-h treatment). In BR16, the Gmdrebla had the same profile as Gmgols, suggesting that the gene can regulate Gmgols under water-stress conditions, and also the other genes in the cascade.

The two soybean genotypes displayed differences in the expression of the genes analyzed, showing that MG/BR46 has mechanisms to detect water stress more promptly than does BR16. The molecular differences detected between these two genotypes permit the manipulation of important soybean genotypes by genetic engineering to produce plants that are more tolerant to water stress and that can retain viability for longer periods under drought conditions.

Due to the complexity of the processes of adaptation to cold and drought that are under transcriptional control, it is not surprising that transcription factors represent one of the best targets for genetic engineering plants for improved tolerance to cold and drought (Zhang et al., 2004). Yet, not all transcription factors involved in drought-response signal transduction are appropriate targets for biotechnological intervention. Presumably, post-transduction alterations would be necessary for protein activation in transgenic plants (Shinozaki and Yamaguchi-Shinozaki, 2000).

\section{ACKNOWLEDGMENTS}

Research supported by CAPES. Embrapa Soybean provided laboratory facilities.

\section{REFERENCES}

Baker SS, Wilhelm KS and Thomashow MF (1994). The 5'-region of Arabidopsis thaliana cor15a has cis-acting elements that confer cold-, drought- and ABA-regulated gene expression. Plant Mol. Biol. 24: 701-713.

Bray EA (2004). Genes commonly regulated by water-deficit stress in Arabidopsis thaliana. J. Exp. Bot. 55: 2331-2341.

Downie B, Gurusinghe S, Dahal P, Thacker RR, et al. (2003). Expression of a GALACTINOL SYNTHASE gene in tomato seeds is up-regulated before maturation desiccation and again after imbibition whenever radicle protrusion is prevented. Plant Physiol. 131: 1347-1359.

Ewing B, Hillier L, Wendl MC and Green P (1998). Base-calling of automated sequencer traces using Phred. I. Accuracy assessment. Genome Res. 8: 175-185.

Fowler S and Thomashow MF (2002). Arabidopsis transcriptome profiling indicates that multiple regulatory pathways are activated during cold acclimation in addition to the CBF cold response pathway. Plant Cell 14: 1675-1690.

Gilmour SJ, Zarka DG, Stockinger EJ, Salazar MP, et al. (1998). Low temperature regulation of the Arabidopsis CBF family of AP2 transcriptional activators as an early step in cold-induced COR gene expression. Plant J. 16: 433-442.

Haake V, Cook D, Riechmann JL, Pineda O, et al. (2002). Transcription factor CBF4 is a regulator of drought adaptation in Arabidopsis. Plant Physiol. 130: 639-648.

Haritatos E, Medville R and Turgeon R (2000). Minor vein structure and sugar transport in Arabidopsis thaliana. Planta 211: 105-111.

Johansson I, Karlsson M, Johanson U, Larsson C, et al. (2000). The role of aquaporins in cellular and whole plant water 
balance. Biochim. Biophys. Acta 1465: 324-342.

Kaldenhoff R, Grote K, Zhu JJ and Zimmermann U (1998). Significance of plasmalemma aquaporins for water-transport in Arabidopsis thaliana. Plant J. 14: 121-128.

Kasuga M, Liu Q, Miura S, Yamaguchi-Shinozaki K, et al. (1999). Improving plant drought, salt, and freezing tolerance by gene transfer of a single stress-inducible transcription factor. Nat. Biotechnol. 17: 287-291.

Kasuga M, Miura S, Shinozaki K and Yamaguchi-Shinozaki K (2004). A combination of the Arabidopsis DREB1A gene and stress-inducible rd29A promoter improved drought- and low-temperature stress tolerance in tobacco by gene transfer. Plant Cell Physiol. 45: 346-350.

Kizis D, Lumbreras V and Pages M (2001). Role of AP2/EREBP transcription factors in gene regulation during abiotic stress. FEBS Lett. 498: 187-189.

Kumar S, Tamura K and Nei M (2004). MEGA3: Integrated software for Molecular Evolutionary Genetics Analysis and sequence alignment. Brief Bioinform. 5: 150-163.

Liu JJ, Krenz DC, Galvez AF and de Lumen BO (1998). Galactinol synthase (GS): increased enzyme activity and levels of mRNA due to cold and desiccation. Plant Sci. 134: 11-20.

Maitra N and Cushman JC (1998). Characterization of a drought-induced soybean cDNA encoding a plant defensin. Plant Physiol. 118: 1536.

Martre P, Morillon R, Barrieu F, North GB, et al. (2002). Plasma membrane aquaporins play a significant role during recovery from water deficit. Plant Physiol. 130: 2101-2110.

Maurel C and Chrispeels MJ (2001). Aquaporins. A molecular entry into plant water relations. Plant Physiol. 125: 135-138.

Miller EM and Nickoloff JA (1995). Escherichia coli Electrotransformation. In: Electroporation Protocols for Microorganisms (Nickoloff JA, ed.). Humana Press, Totowa, 105-114.

Pfaffl MW, Horgan GW and Dempfle L (2002). Relative expression software tool (REST) for group-wise comparison and statistical analysis of relative expression results in real-time PCR. Nucleic Acids Res. 30: e36.

Schenk PM, Kazan K, Manners JM, Anderson JP, et al. (2003). Systemic gene expression in Arabidopsis during an incompatible interaction with Alternaria brassicicola. Plant Physiol. 132: 999-1010.

Seki M, Narusaka M, Abe H, Kasuga M, et al. (2001). Monitoring the expression pattern of 1300 Arabidopsis genes under drought and cold stresses by using a full-length cDNA microarray. Plant Cell 13: 61-72.

Shinozaki K and Yamaguchi-Shinozaki K (1996). Molecular responses to drought and cold stress. Curr. Opin. Biotechnol. 7: 161-167.

Shinozaki K and Yamaguchi-Shinozaki K (2000). Molecular responses to dehydration and low temperature: differences and cross-talk between two stress signaling pathways. Curr. Opin. Plant Biol. 3: 217-223.

Shinozaki K and Yamaguchi-Shinozaki K (2007). Gene networks involved in drought stress response and tolerance. $J$. Exp. Bot. 58: 221-227.

Shukla VK and Chrispeels MJ (1998). Aquaporins their Role and Regulation in Cellular Water Movement. In: Cellular Integrations of Signalling Pathways in Plant Development. (Lo Schiavo E, Lat KL, Morelli G and Raikhel NV, eds.). Series Vol. H 104. North Atlantic Treaty Organization Advanced Study Institute. Springer-Verlag, Berlin, 11-21.

Siefritz F, Biela A, Eckert M, Otto B, et al. (2001). The tobacco plasma membrane aquaporin NtAQP1. J. Exp. Bot. 52: 1953-1957.

Stolf R (2007). Identificação e Análise da Expressão de Genes Relacionados com Tolerância à Seca em Soja Através de Microarranjos de DNA e PCR em Tempo Real. Doctoral thesis, Universidade Estadual Paulista Júlio de Mesquita Filho, Jaboticabal.

Tyerman SD, Bohnert HJ, Maurel C, Steudle E, et al. (1999). Plant aquaporins: their molecular biology, biophysics, and significance for plant water relations. J. Exp. Bot. 50: 1055-1071.

Volkov RA, Panchuk II and Schoffl F (2003). Heat-stress-dependency and developmental modulation of gene expression: the potential of house-keeping genes as internal standards in mRNA expression profiling using real-time RT-PCR. J. Exp. Bot. 54: 2343-2349.

Yamada S, Komori T and Imaseki H (1997). cDNA cloning of gamma-thionin from Nicotiana excelsior. Plant Physiol. 115: 314.

Yamaguchi-Shinozaki K and Shinozaki K (1994). A novel cis-acting element in an Arabidopsis gene is involved in responsiveness to drought, low-temperature, or high-salt stress. Plant Cell 6: 251-264.

Zhang JZ, Creelman RA and Zhu JK (2004). From laboratory to field. Using information from Arabidopsis to engineer salt, cold, and drought tolerance in crops. Plant Physiol. 135: 615-621. 